\title{
Effects of vegetation and topography on biomass patterns post-pinewood nematode disturbance in forest landscapes of southern Jiangxi Province, China
}

\author{
Zhibin Fang ( $\boldsymbol{\nabla}$ 1367772067@qq.com ) \\ Jiangxi Normal University Yaohu Campus: Jiangxi Normal University \\ Zhiwei Wu \\ Jiangxi Normal University Yaohu Campus: Jiangxi Normal University \\ Shitao Lin \\ Jiangxi Academy of Forestry \\ Qiang Liu \\ Jiangxi Normal University Yaohu Campus: Jiangxi Normal University
}

\section{Research Article}

Keywords: Bursaphelenchus xylophilus, forest ecosystems, biomass loss, random forest

Posted Date: April 20th, 2021

DOl: https://doi.org/10.21203/rs.3.rs-439838/v1

License: (c) (1) This work is licensed under a Creative Commons Attribution 4.0 International License.

Read Full License 


\section{Abstract}

Background: Assessing changes in forest ecosystems, especially forest biomass changes that occur due to disturbances, is essential for improving global carbon estimates.

Bursaphelenchus xylophilus is an important pest that harms Pinus thunbergii forests, causing a large number of pine trees to wither and resulting in great losses in Pinus thunbergii forest biomass. Studying the factors affecting $P$. thunbergii) biomass losses caused by Bursaphelenchus xylophilus is of great significance in research on forest ecosystem health and climate change. In this study, taking Nankang District, Ganzhou City, Jiangxi Province as the research area, based on field survey data combined with a random forest model, the relative importance of influencing factors on the biomass loss of $P$. thunbergii due to the Bursaphelenchus xylophilus-caused disease was analyzed.

Results: The results revealed the following conclusions: (1) topographic and slope conditions significantly affected the $P$. thunbergii) biomass losses caused by the Bursaphelenchus xylophilus-related disease; (2) the two studied stand factors, vegetation type and vegetation coverage, had little effect on the $P$. thunbergii) biomass losses caused by Bursaphelenchus xylophilus, and (3) the marginal effect diagram showed that the elevation and slope were obviously related to biomass loss; biomass loss was positively related to elevation and negatively related to slope.

Conclusions: Our study demonstrated that topographical factors dominantly affect the spread of the Bursaphelenchus xylophilus-caused disease, in turn causing large $P$. thunbergii forest biomass losses. Therefore, topographic factors affect the prevention and control of the disease caused by Bursaphelenchus xylophilus.

\section{Background}

As an important part of terrestrial ecosystems, forest ecosystems play an irreplaceable role in maintaining biodiversity and regulating the global carbon balance (Kramer et al 1981; Trumbore et al 2006; He et al 2012). Forest biomass is an important indicator used to measure the function of forest ecosystems (Waring and Schlesinger 1985; Logan 2003; Villanueva et al. 2011). Assessments of forest biomass changes have always been an important component of research on global changes (Dixon et al. 1994; Forkuor G et al. 2020).

Insect pests and diseases constitute an important factor causing the loss of forest biomass (Keeling et al 2013). The World Food and Agriculture Organization (FAO) of the United Nations reported that approximately 40 million hectares of forests were affected by pests and diseases in 2015 (FAO 2020). Among these pests, the pine wood nematode [Bursaphelenchus xylophilus (Steiner \& Buhrer) Nickle] causes a very dangerous forest disease (Jones et al. 2013) that has the characteristics of a high fatality rate, a wide range of damages, fast transmission and spread, being difficult to control, and so on. As a result, this species has been listed as the key object of forest pest quarantine measures in many countries and regions (e.g., Japan, South Korea, and Europe) (Kiyohara and Tokushige 1971, Kim et al. 2020). Pine 
wood nematode disease has spread to 18 provinces since it was first discovered in China in 1982 (Yang et al. 2014). Although the Chinese government has launched active initiatives for the prevention and control of the pine wood nematode, the forest biomass losses caused by pine wood nematodes have remained significant for decades. For example, according to the 2020 report of the state forestry administration of the People's Republic of China (http://www.gov.cn/index.htm), the accumulation of wood loss caused by pine wood nematodes in China was approximately 0.68 million acres.

Scholars have studied the spatiotemporal variations (Ye and Giblin-Davis et al. 2007; Hu et al. 2011; Joana M. et al. 2012), pathogenic mechanisms (Mamiya and Kiyohara 1972; Mamiya 1983; Kikuchi et al. 2011), and transmission modes of pine wood nematodes (Linit et al 1988). For example, Katsumi Togashi et al. (2006) studied a transmission model of pine wood nematodes and concluded that the emergence of pine wood nematodes was closely related to the host longicorn species, artificial transportation, and climatic conditions. Research by Chinese scholars has mainly focused on the physiological factors and vectors of pine wood nematode disease (Zhang et al. 2007; Zhao et al. 2007, Huang et al. 2010; Zhao et al. 2016). For example, Long Pan et al. (2020) studied the population characteristics of pine wood nematodes under low-temperature environmental stress, and the results shown an enhanced adaptability of pine wood nematodes to low-temperature conditions (Pan et al. 2020). Pine wood nematodes are biological invasive species; their harm to forest ecosystems is greatly affected by environmental factors. The impacts of environmental factors on the ecological consequences (such as forest biomass losses) of pine wood nematodes need to be studied further.

The Pinus massoniana pine forests in the Nankang District, southern Jiangxi Province, are seriously affected by pine wood nematodes. In 2020, Nankang District was listed by the State Forestry and Grass Administration of China (http://www.gov.cn/) as a key epidemic area of pine wood nematode infection. After the pine wood nematodes invaded the trees, the needles first lost water, faded to green, and then browned; then, the whole plants withered, and all the needles turned red and yellow and, finally, died. The local government strictly followed the national "Technical Plan for Prevention and Control of Pine Wood Nematode" ([2018] No. 110) and implemented projects involving the cleanup and disposal of infected trees to ensure that no diseased trees or pine branches with diameters of $1 \mathrm{~cm}$ or more were left behind. Hidden hazards such as stumps were also removed (https://www.ganzhou.gov.cn/), resulting in the loss of forest biomass. The existing research on pine wood nematodes affecting P.massoniana in Nankang District has mainly focused on surveillance and control (https://www.ganzhou.gov.cn/). Research on the biomass loss caused by pine wood nematodes in this region has not yet been reported.

The amount of biomass lost after a pine wood nematode disturbance differs due to the vegetation and topographic conditions. The specific objectives of this study were as follows: (1) to analyze the differences in the degree of P.massoniana biomass loss caused by pine wood nematodes under different vegetation and topographic conditions; (2) to analyze the relative influences of vegetation and topographic factors on Masson pine biomass loss; and (3) to identify the key factors affecting the biomass loss caused by pine wood nematodes. The results are expected to provide managers with an understanding of the impact and mechanism of pine wood nematodes affecting regional forest biomass. 


\section{Methods}

\subsection{Study area}

This study was conducted in Nankang District, Jiangxi Province, southern China (Fig. 1). The terrain in this region is dominated by mountains and hills and ranges in elevation from 106-1042 m. The climate is a subtropical humid monsoon climate with an average annual rainfall of $1443.2 \mathrm{~mm}$; the monthly average temperature is $8.8^{\circ} \mathrm{C}$ in December and $28.6^{\circ} \mathrm{C}$ in July. The land area of Nankang District is 1722 $\mathrm{km}^{2}$, of which $60.8 \%$ is covered by forests. The main tree species in the study area include Masson pine (Pinus massoniana Lamb.), fir (Cunninghamia lanceolata (Lamb.) Hook.), Schima superba Gardn. et Champ. and maple (Staphylea forrestii Balf. F.).

\subsection{Overall study approaches}

Through field sample surveys, the height and diameter at breast height (DBH) of each tree in each sample plot (20 m $\times 20 \mathrm{~m}$ in size) were obtained. Information on the terrain factors (slope, slope position, aspect, and elevation) and stand factors (canopy closure and forest type) of each plot was also obtained. Based on stand biomass models, the biomass of each tree in each sample plot was calculated. The Masson pine biomass loss was obtained using the proportion of the total biomass of the diseased wood. Duncan's multiple comparison method was used to evaluate the differences in the biomass losses that occurred under different vegetation and terrain conditions. We used the random forest model to analyze the relative importance (to obtain the contribution rate of each factor to the biomass loss) and then identified the key factors. A marginal effect analysis was used to derive the trend of the influence of each factor on Masson pine biomass loss.

\subsection{Sampling and experimental design}

We obtained field data from 120 plots $(20 \mathrm{~m} \times 20 \mathrm{~m}$ in size) in September 2020 (Fig. 3). These plots were representative of the major forest types and topographic conditions in the study area (Table 1). The latitude and longitude at the center of each sample plot were recorded, and GPS equipment was used to record the slope, elevation, and aspect of each sample plot. The height and DBH of each tree in each 20 $\mathrm{m} \times 20 \mathrm{~m}$ sample plot were investigated. The Masson pine forests in Nankang District were all aerially seeded from 1965 to 1975 , so the forest stands and stand ages in the area are essentially the same. The two statistics had no practical significance, so the stand age and stand composition were not considered. 
Table 1

Plot information

\begin{tabular}{|lllllll|}
\hline Index & Slope & Elevation & $\begin{array}{l}\text { Canopy } \\
\text { closure }\end{array}$ & Aspect & $\begin{array}{l}\text { Slope } \\
\text { position }\end{array}$ & $\begin{array}{l}\text { Forest } \\
\text { type }\end{array}$ \\
\hline Sequential statistics & & & & & & \\
\hline Minimum & 11 & 122 & 0.4 & - & - & - \\
\hline 1st quartile & 16 & 163.8 & 0.7 & - & - & - \\
\hline Median & 18 & 179 & 0.8 & - & - & - \\
\hline 3rd quartile & 23 & 219.2 & 0.8 & - & - & - \\
\hline Maximum & 45 & 474 & 0.9 & - & - & - \\
\hline Arithmetic mean & 20.27 & 203.48 & 0.76 & - & - & - \\
\hline Standard deviation & 6.54 & 69.44 & 0.08 & - & - & - \\
\hline $\begin{array}{l}\text { Skewness } \\
\text { coefficient }\end{array}$ & 1.28 & 1.85 & -0.85 & - & - & - \\
\hline Kurtosis coefficient & 1.59 & 3.12 & 3.19 & & - & - \\
\hline
\end{tabular}

\subsection{Data preprocessing}

In accordance with the "Technical Regulations for the Continuous Inventory of National Forest Resources (2014)", we quantified the terrain and forest stand factors as follows (Table 2).

Table 2

Data quantification

Factor Factor Classification
type

Slope $\quad 1$ gentle slopes $\left(6-15^{\circ}\right), 2$ moderate slopes $\left(16-25^{\circ}\right), 3$ steep slopes $(26-$ $\left.35^{\circ}\right)$, 4 very steep slopes $\left(36-45^{\circ}\right)$, and 5 dangerous slopes $\left(\geq 46^{\circ}\right)$

Terrain Aspect 1 sunny slope, 2. semi-sunny slopes, 3 semi-shady slopes, and 4 shady factors slopes

Slope $\quad 1$ uphill, 2 mid-slope, 3 downhill position

Stand Elevation 1 0-200 meters, 2 200-400 meters, 3 400-600 meters, $4>999$ meters factors

Forest 1 pure Masson pine forest, 2 mixed forests

type

Canopy 1 medium $(0.4 \sim 0.69), 2$ dense $(\geq 0.7)$ closure 
(1) Terrain factors

The sample plot slopes were divided into five categories: 1 represented a gentle slope $\left(6-15^{\circ}\right), 2$ represented a moderate slope $\left(16-25^{\circ}\right), 3$ represented a steep slope $\left(26-35^{\circ}\right), 4$ represented a very steep slope $\left(36-45^{\circ}\right)$, and 5 represented a dangerous slope $\left(\geq 46^{\circ}\right)$. In regard to the slope aspect, 1 was used to represent a sunny slope, 2 was used to represent a semi-sunny slope, 3 was used to represent a semishady slope, and 4 was used to represent a shady slope. The slope positions were divided into three categories: 1 for uphill, 2 for mid-slope, and 3 for a downhill position. The elevation was divided into four levels: 1 for elevations from 0-200 m, 2 for elevations form 200-400 m, 3 for elevations from 400-600 $\mathrm{m}$, and 4 for elevations $>999 \mathrm{~m}$.

\section{(2) Stand factors}

The forest types were classified into two categories: pure Masson pine forest and mixed Masson pine forest, where 1 represented a pure Masson pine forest and 2 represented a mixed forest with Masson pine. The canopy density was divided into greater than 0.7 and less than 0.7 .

\subsection{Calculation of forest biomass loss}

A binary (tree height and DBH) standing tree biomass model (Table 3) from the "People's Republic of China Forestry Industry Standards" (LY/T2263-2014, LY/T2264-2014, LY/T2260-2016) was used to calculate the biomass of each tree in each survey plot (including those infected with and uninfected with pine wood nematode disease). The biomasses of the whole sample plots and the biomass of each pine tree infected with pine wood nematode disease were counted (Regulations on Continuous Inventory of National Forest Resources et al. 2014).

Table 3

Tree biomass modes of dominant species

\begin{tabular}{|l|l|}
\hline Species & Binary model \\
\hline Pinus thunbergii & $\mathrm{M}_{\mathrm{A}}=0.066615 \mathrm{D}^{2.09317} \mathrm{H}^{0.49763}(\mathrm{D} \geq 5)$ \\
\hline Cunninghamia lanceolata & $\mathrm{M}_{\mathrm{A}}=0.117268 \mathrm{D}^{1.74179} \mathrm{H}^{0.49763}(\mathrm{D}<5)$ \\
\hline Schima superba & $\mathrm{M}_{\mathrm{A}}=0.032718 \mathrm{D}^{2.11093} \mathrm{H}^{0.60212}(\mathrm{D} \geq 5)$ \\
\hline Note: $\mathrm{D}$ : diameter at breast height; $\mathrm{H}$ : height & $\mathrm{M}_{\mathrm{A}}=0.173824 \mathrm{D}^{1.07322} \mathrm{H}^{0.60212}(\mathrm{D}<5)$ \\
\hline Biomass of plagued trees/biomass of all trees in the sample plot $\mathrm{x} 100 \%$ \\
\hline
\end{tabular}




\subsection{Statistical analysis}

All statistical analyses were conducted in $\mathrm{R}$ version 4.0.4. First, we used Duncan's multiple comparison method to analyze whether there was a significant difference in the biomass losses of Masson pine under different vegetation and topographic conditions. Duncan's multiple comparison method is a nonparametric comparison method that analyzes differences among groups and has been widely used in biological and ecological applications for multiple comparison analysis research (Warton et al. 2012, Kopelman et al. 2015). Duncan's multiple comparison method was performed using the laercio package in $\mathrm{R}$ language (Silva et al. 2010).

We used the random forest (RF) model to evaluate the relative effects of topographic and vegetation factors on P.massoniana biomass loss. The random forest is an integrated algorithm that uses the bootstrap resampling method to extract multiple samples from an original sample and generates an independent decision tree for each sample (Liaw et al. 2002). The random forest calculates the influence of each variable on the heterogeneity of the observed value at each node of the classification tree through the Gini index to compare the importance of each variable. The larger the value is, the greater the importance of the variable is. The randomForest package in $\mathrm{R}$ language was also used in this study (Breiman and Cutler et al. 2008).

A marginal effect analysis was used to reveal the trend of the contribution of each influencing factor to Masson pine biomass loss. In this study, the partialPlot function was used to plot the contribution of each influencing factor to the overall biomass loss.

\section{Results}

\subsection{Statistical description}

In all the surveyed sample plots, the biomass loss rate caused by pine wood nematodes was between $5 \%$ and $78 \%$, with an average value of $19.3 \%$. A standard deviation of 0.134 was recorded. The distribution was skewed to the right (skewness +2.7 ), showing more positive values than negative values. There were 81 plots with biomass loss rates between $5 \%$ and $20 \%$ and 32 plots with biomass loss rates ranging from $20-34 \%$. The loss rates of the remaining plots ranged from $34-78 \%$ (Table 4 ). 
Table 4

Biomass loss information

\begin{tabular}{|ll|}
\hline Statistic & Biomass loss rate \\
\hline Minimum & 0.057 \\
\hline 1st quartile & 0.11 \\
\hline Median & 0.15 \\
\hline 3rd quartile & 0.22 \\
\hline Maximum & 0.77 \\
\hline Arithmetic mean & 0.19 \\
\hline Standard deviation & 0.13 \\
\hline Skewness coefficient & 2.69 \\
\hline Kurtosis coefficient & 7.87 \\
\hline
\end{tabular}

\subsection{Differences in biomass loss rates among stands and topographic factors}

Duncan's multiple comparison analysis showed that significant differences existed in biomass losses among sample plots with different topographic and forest stand factors (Fig. 4). Significant differences were determined in biomass loss between steep slopes and very steep slopes; the biomass loss was higher on steep slopes. Sunny slopes and shaded slopes showed a statistically significant difference, and the biomass loss was higher on sunny slopes than on shaded slopes. Between mid-slope and upslope plots, the biomass loss was higher in the mid-slope position. Duncan's multiple comparison showed a significant difference in biomass losses between the elevations of $400-600 \mathrm{~m}$ and $0-400 \mathrm{~m}$; the biomass loss was higher in the high hills than in those closer to sea level. Conversely, there was no obvious difference observed in biomass losses among different forest types or different canopy closures.

\subsection{The relative importance of different influencing factors}

A random forest model was used to calculate the relative importance of the influencing factors (Fig. 5). From the ranking of the impact factors shown in Fig. 5, we can see that the importance different among different impact factors. The factors influencing Masson pine biomass loss, in order of importance, were the elevation, slope, canopy closure, slope aspect, slope position, and forest type of the plots. The overall relative importance of the topographic factors were higher than those of the forest type factors.

\subsection{The marginal effects of each impact factor}

The marginal effect of each influencing factor on Masson pine biomass loss is shown in Fig. 6 . As the elevation increased, the marginal effect curve also showed a rising trend, indicating a positive correlation between elevation and biomass loss; with an increase in the slope, the marginal effect curve of biomass loss showed a declining trend, indicating that the slope and biomass loss were negatively correlated. In 
terms of the slope position, the marginal effect value of the middle slope position was the highest, while those of the downslope position and the upslope position were lower. The marginal effect first increased and then dropped with the changing slope position. Regarding the slope aspect, the highest marginal effect value was obtained for the sunny slope, and the differences among the values of the semi-sunny slope, semi-shady slope, and shady slope were very small. There was no obvious difference between the marginal effect values of the mixed forest and pure forest, and this factor had little impact on biomass loss. The changes in the marginal effect value between moderate canopy closure and dense canopy closure were similar to the forest type results; the difference between the two was very small impact of this factor on biomass volume loss was also small.

\section{Discussion}

As a statistical method, the random forest method is widely used in ecological research to address the complex relationships between multidimensional data and variables (Prasad et al 2006; Morera et al. 2020). For example, Iverson $L R$ et al. (2008) used a random forest model to analyze the potential habitats of 134 eastern tree species in the United States under six climatic conditions. Random forest classification and regression can process more complex ecological data than generalized linear models (De'ath et al. 2000). Other studies have also suggested that errors can gradually converge when the number of classification trees in a random forest decision tree becomes sufficiently large to improve the accuracy of the model (Breiman 2001). In studies of biological invasive species, researchers have confirmed that the most important variables influencing invasive species as derived by random forest methods were consistent with those reported in previous studies by scholars (Cutler et al. 2007).

This study showed that the average biomass loss rate of all sample plots was $19.3 \%$, indicating that pine wood nematodes have a great impact on the regional forest ecosystem. Similar findings have also shown that biological invasions affect the productivity of forest ecosystems, and productivity also changes with biomass losses (Lovet et al. 2006). The biomass loss showed a right-biased direction, indicating that the overall biomass loss of the sample plots was relatively high. It is necessary to understand the formation mechanism of the regional environmental conditions that cause extreme biomass losses. In addition, many studies have also shown that Masson pine biomass displays a downward trend after a Masson pine ecosystem is affected by pine wood nematodes, and biomass loss continues to expand with artificial felling and replacement with other tree species (Spiegel and Leege 2013).

This study showed that the slope and elevation of the sample plots were the most significant factors influencing biomass loss (Fig. 5). With an increasing slope, the biomass loss caused by pine wood nematodes first increased and then decreased, and the overall trend increased. This was because an increase in slope reduces the accumulation of organic matter in soils, affecting the growth of the pest host, Pinus massoniana. In addition, an increase in slope usually reduces the soil water content and affects the occurrence of nematodes. For example, Suzuki and Kiyohara (1978) and other scholars (1983) obtained similar results after studying the emergence of pine wood nematodes under soil water stress. The elevation of the sample plots was positively correlated with the biomass loss caused by pine 
wood nematodes; biomass loss did not occur at low elevations, the losses increased at mid-high elevations, and pests did not occur when the elevation continued to increase. The occurrences of wood nematodes yielded similar results. Elevation was positively correlated with the biomass loss caused by pine wood nematodes. This could be due to the transmission ability of the pests, the behavioral characteristics of the pine wood nematode carrier A. longiflora, and the temperature drop that occurs with an increase in elevation (Zhang et al. 2007). A growing number of studies have shown that temperature has a controlling effect on the occurrence of pine wood nematodes (Hashimoto et al. 1976). It was observed during the survey conducted in this study that the aspect and position of the slope of the sample plots also had certain impacts on the biomass loss. The biomass loss caused by pine wood nematodes differed among different aspects. The biomass loss was higher in the sunny aspect than that in the shaded aspect. It was found that pine wood nematodes harmed Masson (Dwinell et al. 2003); as a result, different slope positions had different effects on the biomass losses caused by pine wood nematodes. The biomass loss of the middle slope position was higher than those of the downslope position and the upslope position. The organic matter in the soils of the middle slope position accumulated to a greater extent than those upslope or downslope, and the temperature of the middle slope position was suitable for the pest insects, leading to high biomass loss rates occurring after pest infestations (Ryss et al. 2011). On the other hand, studies on pine wood nematodes niches in China and the established pine wood nematode spread model have also shown that features such as elevation and temperature are important factors affecting the spatial distribution of pine wood nematodes (Wu and $\mathrm{Li}$ 2009).

Figure 7 shows that the sample plots containing pine wood nematodes at elevations of approximately 250 meters accounted for a large proportion of the total number of sample plots, and the proportions of biomass losses were highest in these sample plots. No pine wood nematode pests were observed in the areas below $100 \mathrm{~m}$ or above $500 \mathrm{~m}$, resulting in slight biomass losses.

The stand factor had little effect on the biomass loss caused by pine wood nematodes. Regarding the forest type and canopy density, whether the sample plot contained a pure forest or a mixed forest, the degree of pine wood nematode occurrence was essentially the same for both moderate-canopy-density and high-canopy-density plots. This result was similarly to the results reported in other studies. For example, pine wood nematodes have been observed finding and invading Masson pine trees in mixed forests within short distances (Yoshimura, Akiko et al. 1999, Togashi and Shigesada 2006). This is mainly due to the biological characteristics of pine wood nematode and the behavioral characteristics of the host longhorn beetle; because of these characteristics, pine wood nematodes can pass through short distances in non-Masson pine forests. When the density of a Masson pine forest is too low or too high and the host longhorn beetle density is too low, the emergence of pine wood nematodes becomes difficult (Kishi Y 1995; Takasu et al. 2000). The local government is supposed to treat infected Masson pine stands every year to reduce the spread of the Masson pine disease. However, it is difficult to construct operations in areas with high elevations, steep slopes, and high canopy closures. If infected areas are not controlled in the coming years, the spread of pine wood nematode disease will be aggravated, resulting in large losses. 
This study showed that terrain factors are more important than stand factors in general; temperature and soil moisture are mainly affected by terrain factors, and temperature and soil moisture are the most important factors affecting the occurrence of pine wood nematodes. Mamiya and other researchers in Japan and Europe also arrived at similar conclusions (Rutherford, Mamiya et al. 1990; Ikegami and Jenkins 2018). During the investigation of 120 sample plots, it was found that topographical factors were more important than stand factors for pest control, and this research was significance in guiding management practices. In the actual prevention, control, and management of pine wood nematode disease, attention should be given to the healthy cultivation of Masson pine trees, and healthy pine trees should be maintained. The growth of pine trees requires water to improve the resistance of the trees to disease. A previous study also found that high biomass losses occurred approximately 100 meters around roads; this result may be related to the local furniture manufacturing industry and to other manual transportation practices in the study area.

In this study, the estimation of biomass loss from the P.massoniana disease caused by pine wood nematodes and the correlation analysis of biomass loss with environmental factors on the plot scale provided a reference for estimating large-scale pest-related biomass losses and spatiotemporal changes in pest-related biomass losses. However, climatic conditions also lead to the aggravation and spread of pine wood nematodes and biomass losses (Enda and Mamiya 1972; Mcgawley E C et al. 1985; lki T et al. 2020). This paper did not analyze the correlations between meteorological conditions or climatic factors and the degree of pine biomass loss; therefore, the results obtained in this paper had certain limitations. In future work, we can obtain meteorological data to analyze biomass losses in Masson pine forests and analyze the Masson pine biomass losses caused by pine wood nematodes more comprehensively.

\section{Conclusions}

Pine wood nematodes pose a threat to forest ecosystems and forest biomass. To prevent the spread of pine wood nematodes, their transmission mechanism, including internal transmission factors and external environmental factors, must be determined. The determination of the transmission mechanism would not only help in understanding pine wood nematodes but would also provide information relevant for pest management. This study estimated the biomass losses resulting from pine wood nematodecaused P.massoniana diseases and included a correlation analysis with environmental factors on the sample scale, thereby leading to the following conclusions: 1) topographic factors and forest stand factors affect the P.massoniana biomass losses resulting from pine wood nematode-caused disease differently; 2) topographical factors have a greater impact on pest-related biomass losses caused by pine wood nematodes than forest stand factors; 3 ) the marginal effect diagram shows that elevation and slope were obviously related to biomass losses; biomass losses were positively related to elevation and negatively related to slope.

\section{List Of Abbreviations}


DBH: diameter at breast height; FAO: the World Food and Agriculture Organization; RF: random forest; P.massoniana: Pinus massoniana; P.thunbergii: Pinus thunbergii

\section{Declarations}

\section{Ethics approval and consent to participate}

Not applicable

\section{Consent for publication}

Not applicable

\section{Availability of data and material}

The datasets used and/or analyzed during the current study are available from the corresponding author on reasonable request.

\section{Competing interests}

The authors declare that they have no competing interests.

\section{Funding}

This study was funded by the National Natural Science Foundation of China (No. 31960253).

\section{Authors' contributions}

Zhiwei Wu and Shitao Lin designed the experiments; Zhibin Fang and Qiang Liu performed the experiments; Zhibin Fang analyzed the data and wrote the paper. All authors have read and approved the final manuscript.

\section{Author information}

School of Geography and Environment \& Ministry of Education's Key Laboratory of Poyang Lake Wetland and Watershed Research, Jiangxi Normal University, Nanchang 330022.

\section{References}

Akbulut S , Stamps WT (2012). Insect vectors of the pinewood matode: a review of the biology and ecology of Monochamus species. Forest Pathology.https://doi.org/10.1111/j.1439-0329.2011.00733.x

Breiman L (2001). Randomforests, Machine Learning 45(1).https://doi.org/10.1023/A:1010933404324 
Breiman L, Cutler A, Liaw A (2008). randomForest: Breiman and Cutler's Random Forests for Classification and Regression. The R Journal

Cutler, DR, Edwards (2007). "Random forests for classification in ecology." Ecology 2007,88(11)(-): 27832792. https://doi.org/10.1890/07-0539.1

De'ath, Glenn, Fabricius (2000). Classification and regression trees: A powerful yet simple technique for ecological data analysis.Ecology.https://doi.org/10.1890/0012-9658(2000)081[3178:CARTAP]2.0.C0;2

Dixon RK, Solomon A M, Brown S (1994). Carbon pools and flux of global forest ecosystems. Science (New York, N.Y.) 263(5144): 185-190. https://doi.org/10.1126/science.263.5144.185

Dwinell, L. D (2003). The pinewood nematode:Regulation and Mitigation. Annual Review of Phytopathology 35(1): 153.https://doi.org/10.1146/annurev.phyto.35.1.153

Enda, N. , Y. Mamiya (1972). Transmission of Bursaphelenchus Lignicolus (Nematoda: Aphelenchoididae) By Monochamus Alternatus (Coleoptera: Cerambycidae).Nematologica 18(2): 159162.https://doi.org/10.1163/187529272X00395

FAO (2020). Global Forest Resources Assessments. 25

Forkuor G, Zoungrana JBB,Dimobe K, Ouattara B, Vadrevu KP, Tondoh, J E (2020). Above-ground biomass mapping in West African dryland forest using Sentinel-1 and 2 datasets - A case study. Remote Sensing of Environment 236.DOI: 10.1016/j.rse.2019.111496

Gary M. Lovett,., Mary A, Arthur, Kathleen C, Weathers, Ross D Fitzhugh (2006). Forest Ecosystem Responses to Exotic Pests and Pathogens in Eastern North America. BioScience 56(5): 395405.https://doi.org/10.1641/0006-3568(2006)056[0395:FERTEP]2.0.CO;2

Hashimoto H. (1976). Pathological study of the pine wilting disease caused by Bursaphelenchus lignicolus under different conditions of watering. Trans Jpn for Soc $\mathbf{8 7}$

Hu YQ., Kong XC, Wang XR. (2011). Direct PCR-based method for detecting Bursaphelenchus xylophilus, the pine wood nematode in wood tissue of Pinus massoniana. Forest Pathology 41(2): 165-168. https://doi.org/10.1111/j.1439-0329.2010.00692.x

Huang, QX., Cheng XY, Mao ZC (2010). MicroRNA Discovery and Analysis of Pinewood Nematode Bursaphelenchus xylophilus by Deep Sequencing. Plos One 5(10).

https://doi.org/10.1371/journal.pone.0013271

Ikegami, M. , T. A. R. Jenkins (2018). Estimate global risks of a forest disease under current and future climates using species distribution model and simple thermal model - Pine Wilt disease as a model case. Remote Sensing of Environment 409: 343-352. https://doi.org/10.1016/j.foreco.2017.11.005 
Iki T., Matsunaga K, Hirao T (2020). Effects of Temperature Factors on Resistance against Pine Wood Nematodes inPinus thunbergii, Based on Multiple Location Sites Nematode Inoculation Tests. Forests 11(9). https://doi.org/10.3390/f11090922

Iverson LR., Prasad A M, Matthews S N (2008). Estimating potential habitat for 134 eastern US tree species under six climate scenarios. Forest Ecology and Management 254(3): 390-406.

https://doi.org/10.1016/j.foreco.2007.07.023

Jianjun Z, Runzhi Z, Jingyuan C (2007). Species and their dispersal ability of as vectors to transmit. Journal of Zhejiang Forestry College. http://zjlx.chinajournal.net.cn

He JS (2012). Carbon cycling of Chinese forests: From carbon storage, dynamics to models. Science China Life Sciences. https://doi.org/10.1007/s11427-012-4285-z

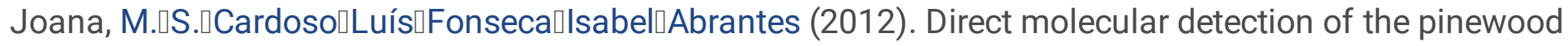
nematode, Bursaphelenchus xylophilus, from pine wood, bark and insect vector. European Journal of Plant Pathology. https://doi.org/10.1007/s10658-011-9915-y

Jones J T, Haegeman A, Danchin EGJ,Gaur H S, Helder J, Jones, MGK, Kikuchi T(2013). Top 10 plantparasitic nematodes in molecular plant pathology. Molecular Plant Pathology 14(9): 946-961. https://doi.org/10.1111/mpp.12057

Keeling CL,Yune MMS;Liao NY (2013). Draft genome of the mountain pine beetle, Dendroctonus ponderosae Hopkins, a major forest pest.Genome biology 14(3): R27.https://doi.org/10.1186/gb-2013$14-3-r 27$

Kikuchi T, Cotton JA, Dalzell JJ (2011). Genomic Insights into the Origin of Parasitism in the Emerging Plant Pathogen Bursaphelenchus xylophilus.Plos Pathogens

7(9).https://doi.org/10.1371/journal.ppat.1002219

Kim BN, Kim JH, Ahn JY (2020). A short review of the pinewood nematode,Bursaphelenchus xylophilus. Toxicology and Environmental Health Sciences 12(4): 297-304. https://doi.org/10.1007/s13530-02000068-0

Kiyohara T,Tokushige Y (1971). Inoculation Experiments of a Nematode,Bursaphelenchus sp., onto Pine Trees. Journal Of The Japanese Forestry Society 53(7): 210-

218.https://doi.org/10.11519/jjfs1953.53.7_210

Kishi Y (1995). The pine wood nematode and the Japanese pine sawyer.

Kopelman NM, Mayzel J, Jakobsson M,Rosenberg NA, Mayrose I(2015). Clumpak: a program for identifying clustering modes and packaging population structure inferences across $\mathrm{K}$. Molecular Ecology Resources 15(5): 1179-1191. https://doi.org/10.1111/1755-0998.12387 
Kramer PJ (1981). Carbon Dioxide Concentration, Photosynthesis, and Dry Matter Production. Bioence(1): 29-33.https://doi.org/10.2307/1308175

Kuroda K, Ito S (2008). Migration speed of pine wood nematodes and activities of other microbes during the development of pine-wilt disease in Pinus thunbergii. Journal Of The Japanese Forestry Society 74 : 383-389. https://doi.org/10.11519/jjfs1953.74.5_383

Liaw A, Wiener M (2002). Classification and Regression with Random Forest. R News 23(23). http://dx.doi.org/

Linit MJ (1988). Nemtaode-Vector Relationships in the Pine Wilt Disease System. Journal of Nematology 20(2): 227-235. https://doi.org/10.1002/jez.1402460113

Logan J, Regniere J (2003). Assessing the impacts of global warming on forest pest dynamics. Frontiers in Ecology and the Environment 1(3): 130-137. https://doi.org/10.1890/15409295(2003)001[0130:ATIOGW]2.0.CO;2

Mamiya Y (1983). Pathology of the Pine Wilt Disease Caused by Bursaphelenchus xylophilus.Annual Review of Phytopathology 21: 201-220. https://doi.org/10.1146/annurev.py.21.090183.001221

Mamiya Y, Kiyohara T (1972).Description of Bursaphelenchus Lignicolus N. Sp. (Nematoda: Aphelenchoididae) From Pine Wood and Histopathology of Nematode-Infested Trees.Nematologica 18(1): 120-124.https://doi.org/10.1163/187529272X00296

Mcgawley EC, Winchell KL, Jones JP, Birchfield W,Berggren GT (1985). Population Development and Influence of Bursaphelenchus xylophilus on Gliocladium virens. Journal of Nematology 17(1): 69.https://doi.org/65620

Morera A, Aragón JMD囚Bonet JA囚Liang J『De-Miguel S (2020). Performance of Statistical and Machine Learning-Based Methods for Predicting Biogeographical Patterns of Fungal Productivity in Forest Ecosystems. Forest Ecosystems. https://10.21203/rs.3.rs-122045/v1

Pan L, Cui, R, Li, YX, Feng YZ XY(2020). Investigation of Pinewood Nematodes inPinus tabuliformisCarr. under Low-Temperature Conditions in Fushun, China. Forests 11(9). https://doi.org/10.3390/f11090993

Prasad, AM, Iverson, LR, Liaw(2006). Newer classification and regression tree techniques: Bagging and random forests for ecological prediction.Ecosystems 2006,9(2)(-): 181199.https://doi.org/10.1007/s10021-005-0054-1

Regulations on Continuous Inventory of National Forest Resources(2014) Tree biomass models and related parameters to carbon accounting for Pinus massoniana, State Forestry Administration. LY/T 2263-2014: 1-20. 
Rutherford TA, Mamiya Y, Webster JM(1990). Nematode-induced pine wilt disease: factors influencing its occurrence and distribution.Forest Science 36(1): 145-155.https://doi.org/10.1016/0378-1127(90)901588

Ryss AY, Kulinich OA, Sutherland JR (2011). Pine wilt disease: a short review of worldwide research.Forestry Studies in China(02): 132-138.https://doi.org/10.1007/s11632-011-0205-8

Silva LJD (2010ه09ه17). laercio: Duncan test, Tukey test and Scott-Knott test.The R Journal

Spiegel KS, Leege LM (2013). Impacts of laurel wilt disease on redbay (Persea borbonia (L.) Spreng.) population structure and forest communities in the coastal plain of Georgia, USA. Biological Invasions 15(11): 2467-2487. https://doi.org/10.1007/s10530-013-0467-2

Suzuki K, Kiyohara T (1978). Influence of water stress on development of pine wilting disease caused by Bursaphelenchus lignicolus.European Journal of Forest Pathology 8(2).https://doi.org/10.1111/j.14390329.1978.tb00622.x

Takasu F, Yamamoto N, Kawasaki K, Togashi K, Kishi Y, Shigesada N(2000). Modeling the Expansion of an Introduced Tree Disease.Biological Invasions 2(2): 141-150.

https://doi.org/10.1023/A:1010048725497

Togashi K, Shigesada N (2006). Spread of the pinewood nematode vectored by the Japanese pine sawyer: modeling and analytical approaches. Population Ecology 48(4): 271-283. https://doi.org/10.1007/s10144-006-0011-7

Trumbore S (2006). Carbon respired by terrestrial ecosystems - recent progress and challenges. Global Change Biology 12(2): 141-153. https://doi.org/10.1111/j.1365-2486.2006.01067.x

Villanueva, Proupin, Rodriguez-Anon, JA, Fraga-Grueiro, Salgado, Barros(2011). Energetic characterization of forest biomass by calorimetry and thermal analysis. J Therm Anal Calorim. https://doi.org/10.1007/s10973-010-1177-y

Waring RH,Schlesinger WH (1985). Forest ecosystems: concepts and management. Clinical \& Experimental Allergy 75(75): 284. https://doi.org/10.2307/1310524

Warton DI, Duursma RA, Falster DS, Taskinen S(2012). smatr 3-an R package for estimation and inference about allometric lines.Methods in Ecology and Evolution 3(2): 257-259.

https://doi.org/10.1111/j.2041-210X.2011.00153.x

Wu WH,Li MY(2009). Methods for Predicting Potential Habitat of Bursaphelenchus xylophilus based on Ecological Niche Model. Forest Inventory And Planning.34(05): 33-38. http://dx.chinadoi.cn/10.3969/j.issn.1671-3168.2009.05.008 
Yang ZQ, Wang XY, Zhang YN(2014). Recent advances in biological control of important native and invasive forest pests in China.Biological Control. https://doi.org/10.1016/j.biocontrol.2013.06.010

Ye WM, Giblin-Davis RM,Braasch H, Morris K, Thomas WK(2007).Phylogenetic relationships among Bursaphelenchus species (Nematoda : Parasitaphelenchidae) inferred from nuclear ribosomal and mitochondrial DNA sequence data.Molecular Phylogenetics and Evolution 43(3): 1185-1197.

https://doi.org/10.1016/j.ympev.2007.02.006

Yoshimura, Akiko, Kawasaki, Kohkichi (1999). Modeling the spread of pine wilt disease caused by nematodes with pine sawyers as vector.Ecology. https://doi.org/10.1890/0012-

9658(1999)080[1691:MTSOPW]2.0.C0;2

Zhao LL, Zhang XX, Wei, YN, Zhou J,Zhang W,Qin PJ, Chinta S, Kong XB, Liu YP, Yu HY(2016). Ascarosides coordinate the dispersal of a plant-parasitic nematode with the metamorphosis of its vector beetle. Nature Communications 7: 12341. https://doi.org/10.1038/ncomms12341

Zhao L, Wei W Kulhavy, David L, Zhang XY, Sun JH (2007). Low temperature induces two growth-arrested stages and change of secondary metabolites in Bursaphelenchus xylophilus. Nematology 9: 663-670. https://doi.org/10.1163/156854107782024866

\section{Figures}

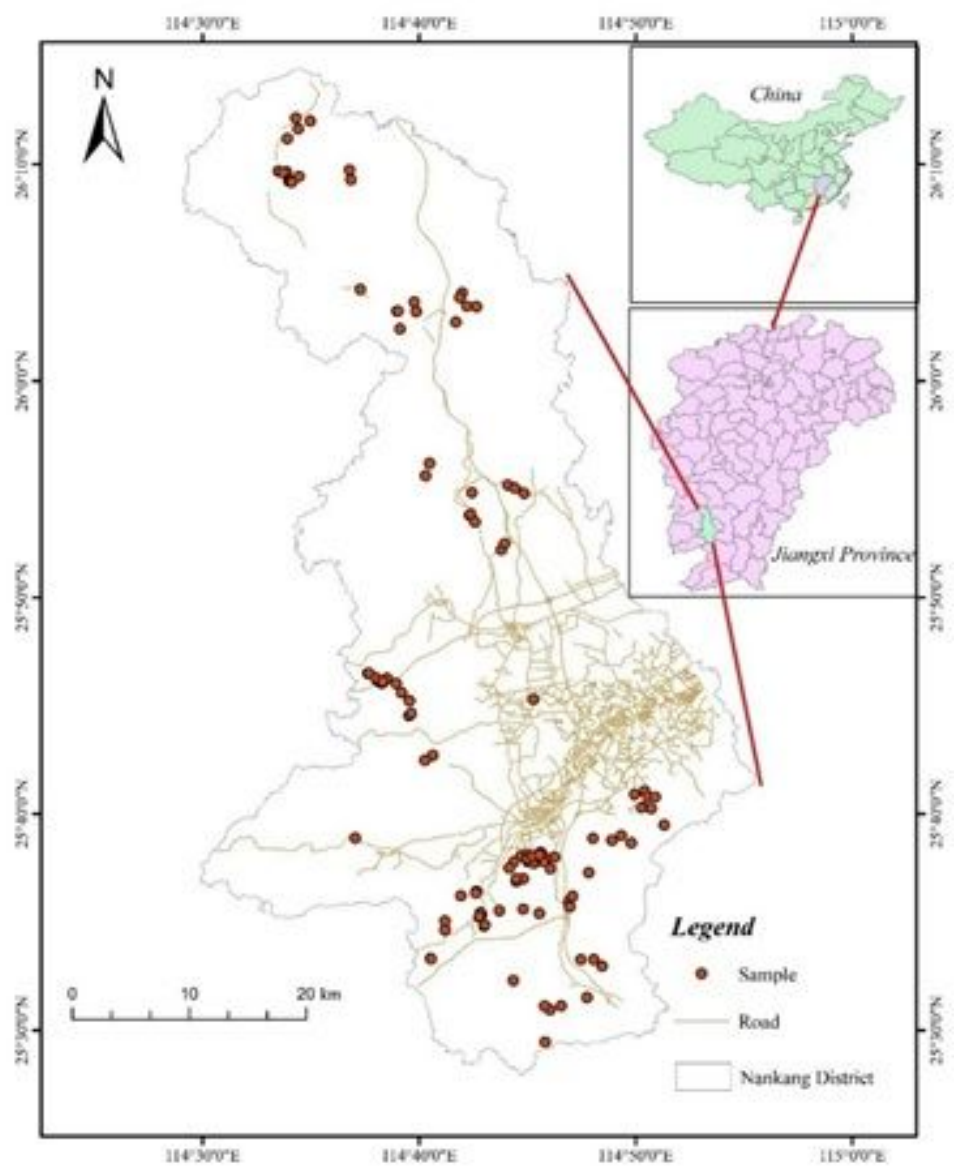


Figure 1

Location and sample point distribution map of Nankang District, Jiangxi Province Note: The designations employed and the presentation of the material on this map do not imply the expression of any opinion whatsoever on the part of Research Square concerning the legal status of any country, territory, city or area or of its authorities, or concerning the delimitation of its frontiers or boundaries. This map has been provided by the authors.

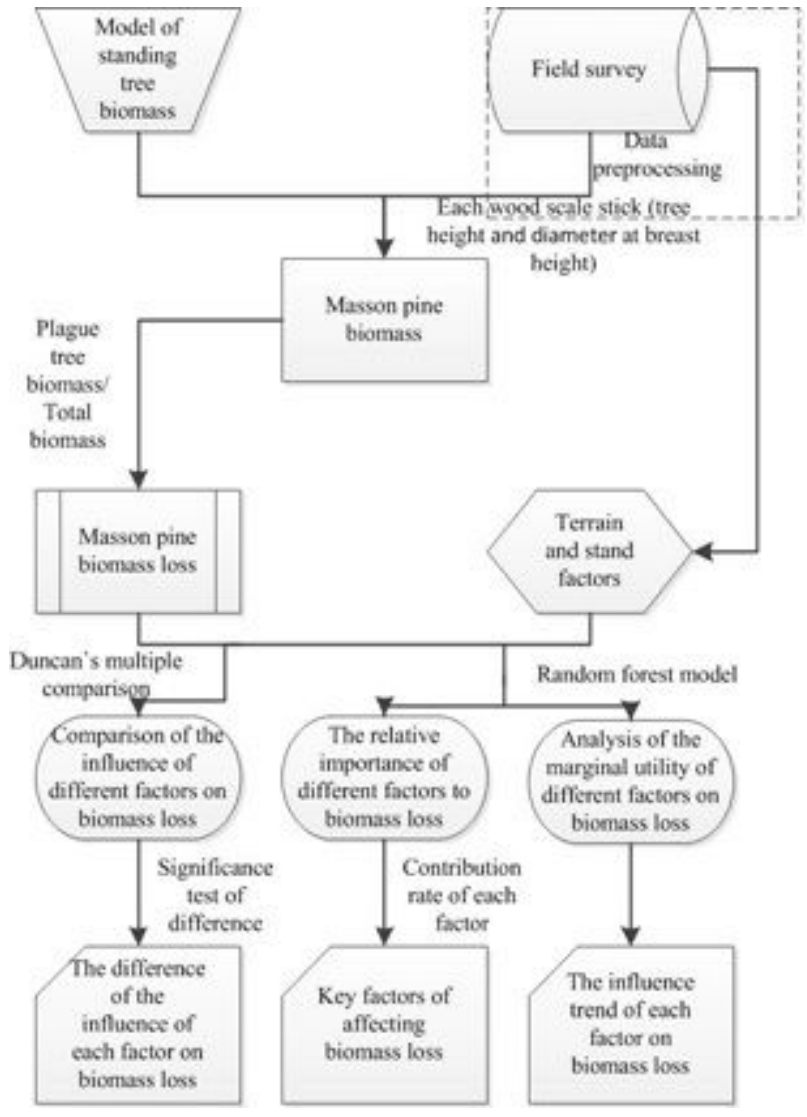

\section{Figure 2}

The overall steps of this study

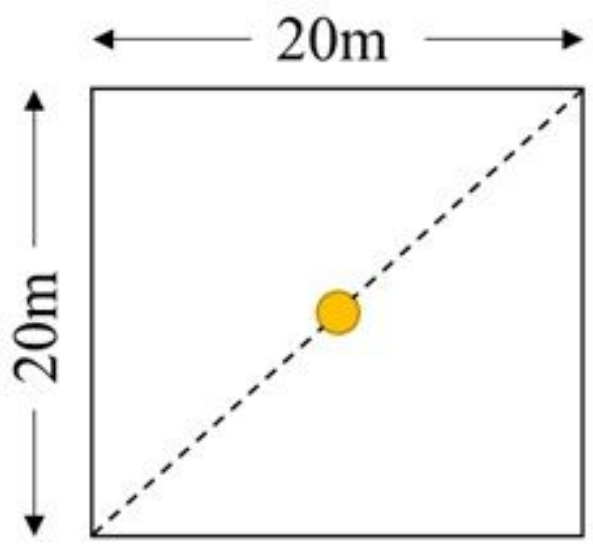

Figure 3 
Sample plot design
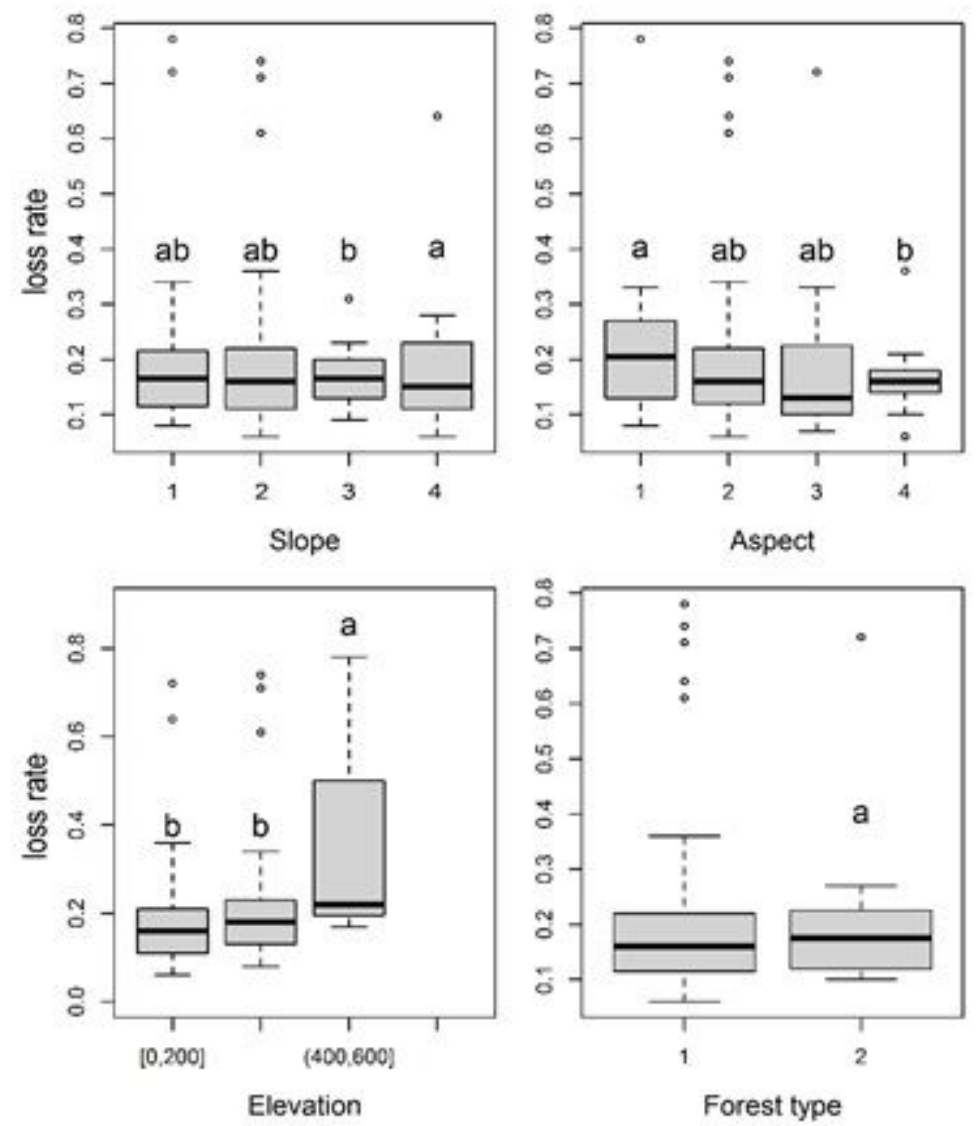
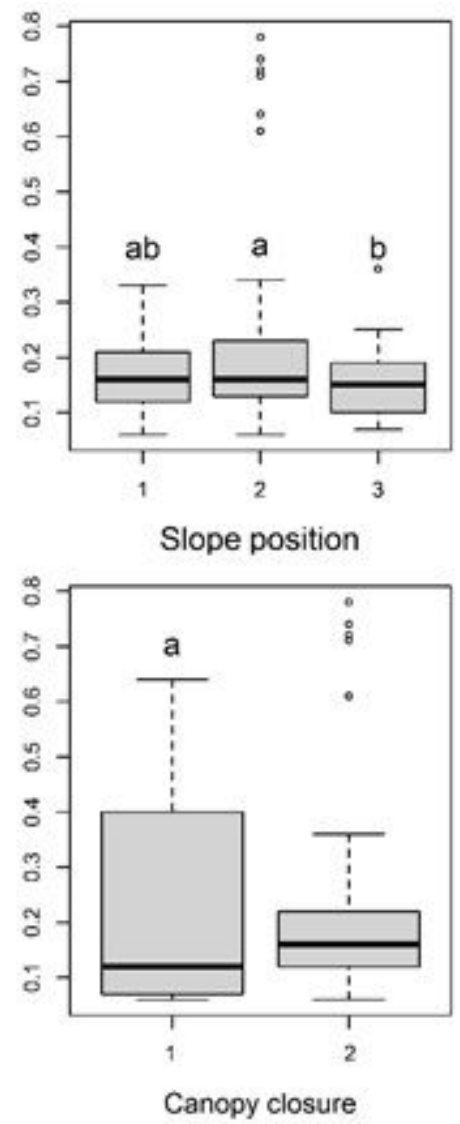

Figure 4

Multiple comparisons of biomass losses under different topographic and stand conditions (different letters in the box indicate significant differences, and the same letters indicate differences that are not significant) 


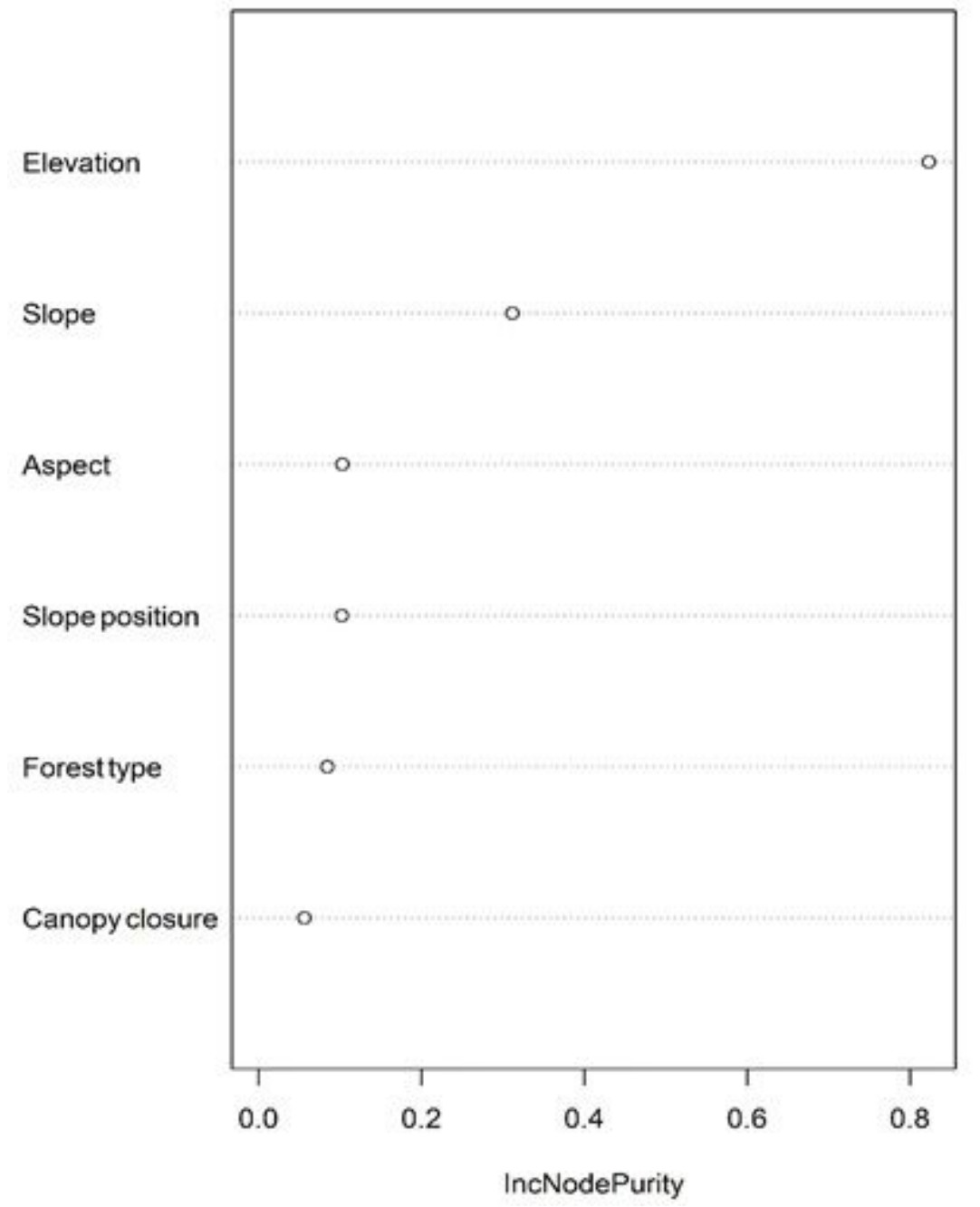

Figure 5

The relative importance of each influencing factor in the random forest model 

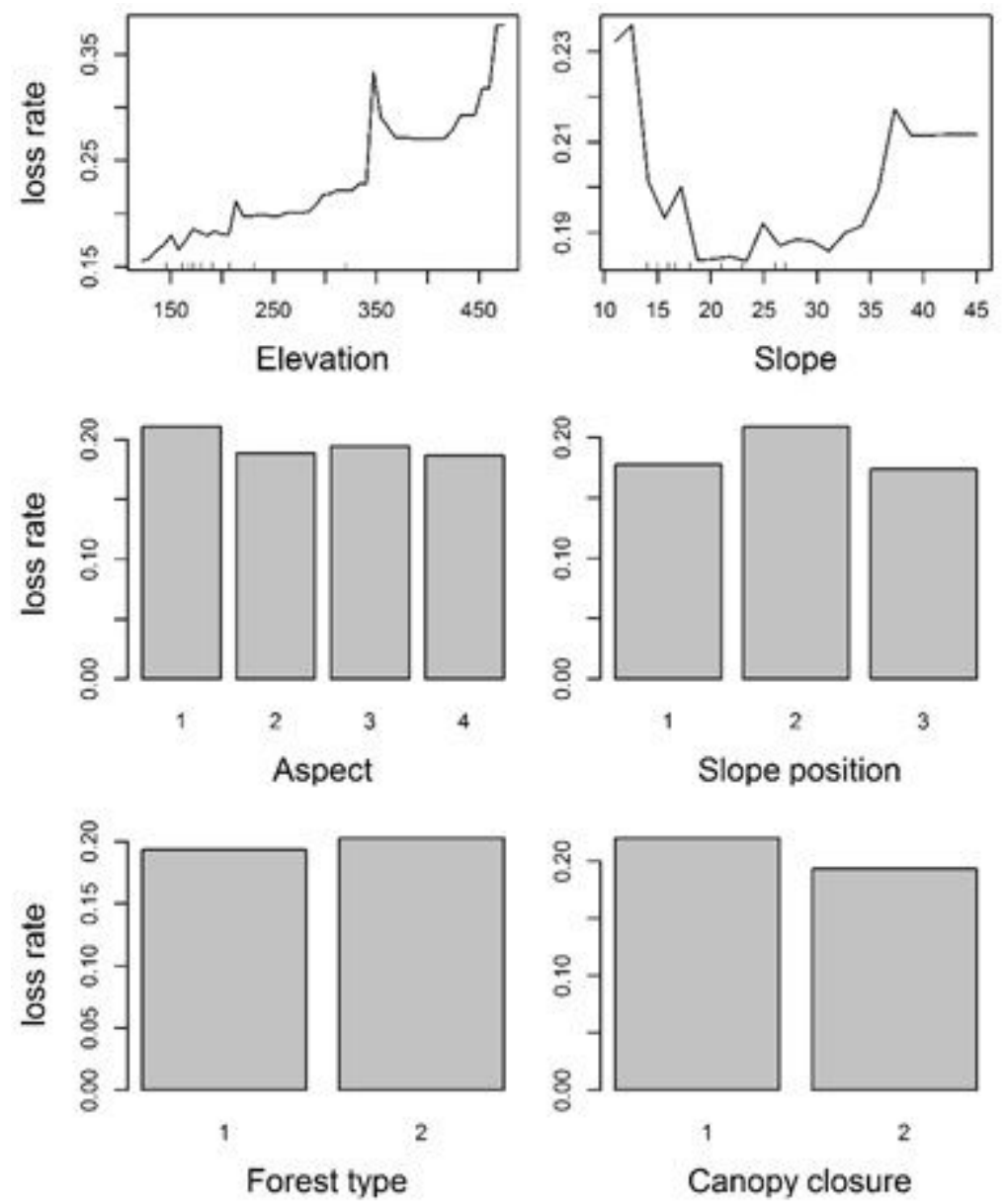

Figure 6

Marginal utility between Pinus thunbergii biomass loss rates and various influencing factors 


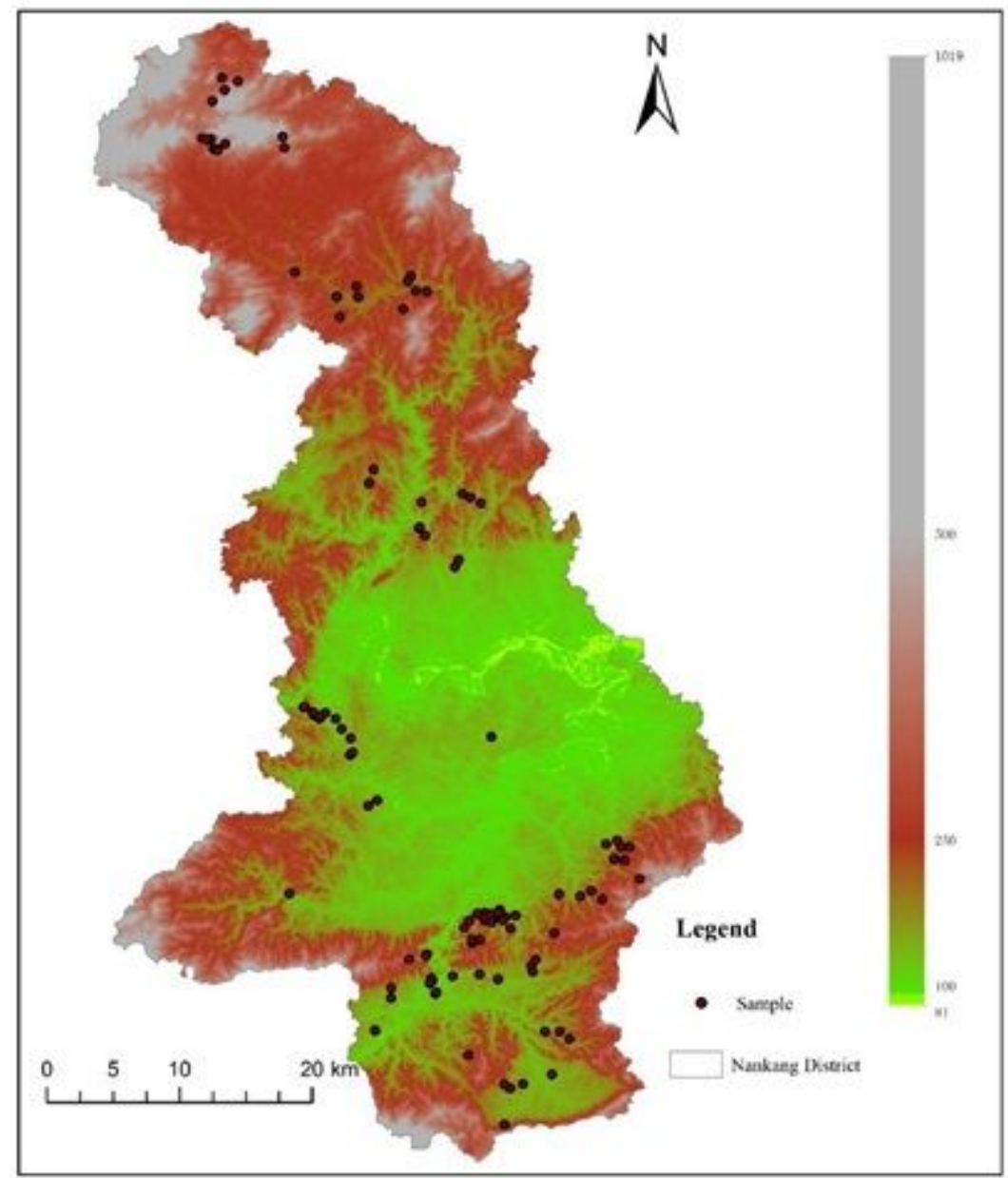

Figure 7

Elevation and biomass loss in Nankang District Note: The designations employed and the presentation of the material on this map do not imply the expression of any opinion whatsoever on the part of Research Square concerning the legal status of any country, territory, city or area or of its authorities, or concerning the delimitation of its frontiers or boundaries. This map has been provided by the authors. 